\title{
Improvement of pathological staging system for neuroendocrine tumors of the lung
}

\author{
Chengxiang $\mathrm{Yi}^{1 \#}{ }^{1 \#}$, Jie Dai ${ }^{1 \#}$, Nan Song ${ }^{1}$, Chunxiao $\mathrm{Wu}^{2}$, Liping Zhang ${ }^{3}$, Yuming $\mathrm{Zhu}^{1}$, Gening Jiang ${ }^{1}$, \\ Helin Zhang $^{4}$, Peng Zhang ${ }^{1}$
}

${ }^{1}$ Department of Thoracic Surgery, Shanghai Pulmonary Hospital, Tongji University, Shanghai, China; ${ }^{2}$ Shanghai Municipal Center for Disease Control and Prevention, Shanghai, China; ${ }^{3}$ Department of Pathology, Shanghai Pulmonary Hospital, Tongji University, Shanghai, China; ${ }^{4}$ Department of Thoracic Surgery, Hebei The Second Hospital of Hebei Medical University, Shijiazhuang, China

Contributions: (I) Conception and design: C Yi, J Dai, N Song; (II) Administrative support: L Zhang, Y Zhu, G Jiang, H Zhang, P Zhang. (III) Provision of study materials or patients: P Zhang; (IV) Collection and assembly of data: C Yi, C Wu; (V) Data analysis and interpretation: C Yi, J Dai; (VI) Manuscript writing: All authors; (VII) Final approval of manuscript: All authors.

\#These authors contributed equally to this work.

Correspondence to: Peng Zhang. Department of Thoracic Surgery, Shanghai Pulmonary Hospital, No. 507, Zhengmin Road, Yangpu District, Shanghai, China. Email: zhangpeng1121@tongji.edu.cn; Gening Jiang. Department of Thoracic Surgery, Shanghai Pulmonary Hospital, No. 507, Zhengmin Road, Yangpu District, Shanghai, China. Email: jgnwp@aliyun.com; Helin Zhang. Department of Thoracic Surgery, Hebei The Second Hospital of Hebei Medical University, No. 53, Huaxi Road, Xinhua District, Shijiazhuang City, China. Email: zhanghelin@hotmail.com.

Background: Currently, the tumor, node, and metastasis (TNM) staging system has a limited value in prognostic stratification for neuroendocrine tumors of the lung (NETL). A specific pathological staging system was therefore explored.

Methods: Two cohorts were assessed: the training cohort was composed of surgically treated patients from the Surveillance, Epidemiologic, and End Results (SEER) database [2004-2015]; the Shanghai cohort included Shanghai resident patients treated at Shanghai Pulmonary Hospital [2009-2018]. Multivariable Cox regression analysis was performed to identify factors associated with overall survival. A new staging system was proposed based on survival tree, and was further compared with the $8^{\text {th }}$ edition of the TNM staging system.

Results: In the training set $(n=3,204)$, multivariate Cox analysis showed that tumor histotype and nodal status were independently associated with survival, but not $\mathrm{T}$ stage. Therefore, by incorporating NETL histotype (G1, low-grade typical pulmonary carcinoids; G2, intermediate-grade atypical pulmonary carcinoids; G3, high-grade large-cell neuroendocrine carcinomas) and $\mathrm{N}$ stage, a new staging system was developed: IA, G1N0; IB, G1N1 or G2N0; II, G1N2, G2N1-2, or G3N0; III, G3N1-2. Five-year survival rates were $91.2 \%, 81.3 \%, 50.2 \%$ and $27.6 \%$ for the new stages IA to III in the validation set $(\mathrm{n}=3,204)$, respectively $(\mathrm{P}<0.001)$. Additionally, the new staging system had significantly better predictive ability than the TNM staging system, in both the SEER [C-index, 0.75 vs. 0.62; net reclassification improvement (NRI), 0.62; integrated discrimination improvement (IDI), 20\%] and Shanghai (IDI, 8\%) cohorts. Based on the new staging system, adjuvant chemotherapy conferred a significantly better survival in stage-III NETL cases (HR $=0.34,95 \%$ CI, 0.25-0.45).

Conclusions: The new pathological staging system can better predict NETL prognosis than the $8^{\text {th }}$ edition of the TNM staging system, with the potential to guide postoperative treatment.

Keywords: Neuroendocrine tumor; TNM stage; lung cancer; survival; adjuvant chemotherapy

Submitted Aug 06, 2020. Accepted for publication Jan 03, 2021.

doi: $10.21037 /$ atm-20-5910

View this article at: http://dx.doi.org/10.21037/atm-20-5910 


\section{Introduction}

Neuroendocrine tumors of the lung (NETL) constitute a unique clinical subgroup of primary pulmonary cancers, with particular morphological, ultrastructural, immunohistochemical and molecular characteristics. Tumor histotype and differentiation are crucial determinants of the clinical behavior of NETL. Well-differentiated NETL consist of low-grade typical pulmonary carcinoids and intermediate-grade atypical pulmonary carcinoids, while poorly differentiated tumors include high-grade large cell neuroendocrine carcinomas and small-cell lung cancer (SCLC) (1). The incidence of neuroendocrine tumors approximates 5.25 cases per 100,000 persons in the United States (2). Owing to the increased lung cancer screening, NETL prevalence currently has the fastest growth (3).

The International Association for the Study of Lung Cancer launched a worldwide tumor, node, and metastasis (TNM) staging project $(4,5)$, and the TNM staging system is used for NETL. However, a recent study pointed out that staging systems for NETL should include histotype (6). Further, the use of tumor size for staging the T-category in lung carcinoids has been questioned (7). Therefore, staging of these tumors needs to be optimized. This study aimed to develop a new pathological staging system that could refine prognostic stratification and guide subsequent treatment in NETL. We present the following article in accordance with the STROBE reporting checklist (available at http://dx.doi. org/10.21037/jgo-20-5910).

\section{Methods}

The study was conducted in accordance with the Declaration of Helsinki (as revised in 2013).

\section{Study population}

Patient data were obtained from the Surveillance, Epidemiologic, and End Results (SEER) database. Inclusion criteria were: site recode "ICD-O-3/WHO 2008" (International Classification of Diseases for Oncology, Third Edition) restricted to "Lung and Bronchus"; histotype pathologically confirmed as typical pulmonary carcinoids $\{$ ICD-O-3 [8240/3] $\}$, atypical pulmonary carcinoids $\{\mathrm{ICD}-\mathrm{O}-3$ [8249/3] or large cell neuroendocrine carcinomas \{ICD-O-3 [8013/3]\} between 2004 and 2015; known patient age, TNM stage, and survival data; surgical treatment. Considering its strong invasion ability and unique pathological characteristics, SCLC was not included in this study (6). Besides, patients whose tumors could not be confirmed for diaphragm invasion status were excluded. TNM staging was converted to the $8^{\text {th }}$ edition of the TNM staging system (5). Low-grade (typical pulmonary carcinoids), intermediate-grade (atypical pulmonary carcinoids) and high-grade (large-cell neuroendocrine carcinomas) neuroendocrine histotypes were designated as G1, G2 and G3, respectively. Overall survival was used as an endpoint of survival. Patients not diagnosed with NETL for the first time were excluded. Finally, 6,408 patients were included.

In the Shanghai cohort, Shanghai resident patients administered lung resection and pathologically confirmed with G1, G2 and G3 histotypes, respectively, at Shanghai Pulmonary Hospital between January 2009 and September 2018 were included. The pathologic diagnosis was confirmed after bronchoscopic examination, percutaneous lung puncture and/or surgical resection according to the 2015 World Health Organization (WHO) classification (1). Patients with no TNM stage assessment or survival data were excluded (Figure S1). According to the National Comprehensive Cancer Network (NCCN) guidelines (8), surgical resection was administered in TNM stage-I to II and select stage-III patients. Adjuvant treatment was routinely recommended for TNM stage-IIB to IIIB patients and individuals with stage IB-IIA large-cell neuroendocrine carcinoma, and comprised 4-6 cycles of a platinum-based doublet therapy.

\section{Study design}

In the SEER cohort, patients were randomly assigned at a $1: 1$ ratio to the training $(n=3,204)$ and validation $(n=3,204)$ sets. In the SEER training set, significant variables were selected to generate a survival tree by hazards ratio (HR) for survival. A new staging system was proposed by incorporating groups with similar HRs and validated in the SEER validation set. Moreover, the new and TNM staging systems were compared in the SEER and Shanghai cohorts. Furthermore, for patients in whom adjuvant chemotherapy is recommended based on the NCCN guidelines (TNM stages IIB to IIIB; IB and IIA large-cell neuroendocrine carcinomas), the value of adjuvant chemotherapy based on the TNM and new staging systems was assessed.

\section{Statistical analysis}

Continuous variables with normal distribution were 
presented as mean \pm standard deviation $(\mathrm{SD})$, and categorical data as number (percentage, \%). Two-tailed $t$-test and the chi-square test were performed to examine the differences in clinical variables between the two sets. Overall survival curves were generated by the KaplanMeier method, and differences were examined by the logrank test. Variables with $\mathrm{P}<0.1$ in univariate analysis and treatment relevant parameters were included in multivariate Cox regression analysis and the random forest (RF) model, respectively. The proportional hazard assumption in the Cox model was tested based on the Schoenfeld residuals, and 1,000 bootstrapping replications were performed. C-index, net reclassification improvement (NRI) and integrated discrimination improvement (IDI) were further used to assess the survival prediction abilities of different staging systems. NRI was calculated from the survival probabilities of the ordered staging systems among those moving up and down the stage classifications (9), and IDI was calculated as the difference in the proportion of explained variation at time $t$ between staging systems (10). A $\mathrm{P}$ value of less than 0.05 was considered statistically significant. Interaction assessments were performed by the likelihood ratio test. Kaplan-Meier curve generation and the log-rank test were performed with GraphPad Prism version 7.00 for Windows (GraphPad Software, Inc., www. graphpad.com). Statistical analysis was performed with the $\mathrm{R}$ version 3.5.3 software (http://www.r-project.org/).

\section{Results}

\section{Establishment of a new staging system in the SEER cobort}

In the SEER training group, 2,361 (73.7\%) patients were identified as G1, $260(8.1 \%)$ as G2 and $583(18.2 \%)$ as G3; based on $\mathrm{N}$ stage, the majority $(86.5 \% ; \mathrm{n}=2,772)$ of patients had N0 tumors. Lobectomy was performed in 2,207 (68.9) patients, and 1,917 (59.8\%) underwent more than 3 regional lymph node samplings. In addition, adjuvant chemotherapy and radiotherapy (RT) were performed in $270(8.4 \%)$ and 108 (3.4\%) patients, respectively (Table 1).

Univariate Cox regression analysis showed that age, race, gender, histology, adjuvant chemotherapy, and TNM stage were all significant variables; however, hazards ratios for survival in TNM stages IA2 to IIA were similar, ranging from 0.96 to 1.33 (IA1 as reference, Table 2). Multivariate Cox analysis revealed that $\mathrm{N}$ stage was independently associated with survival, while $\mathrm{T}$ stage was not. The histotypes G2 (HR =2.42, 95\% CI: 1.81-3.23) and G3 (HR
$=5.89,95 \%$ CI: $4.83-7.19)$ were significantly associated with reduced survival compared with G1. Consistently, histotype and $\mathrm{N}$-stage were significantly associated with survival in the RF model (importance: 0.102, 0.005, Table 2). In subgroup analysis, tumor histotype could better discriminate patient survival in each subgroup of the $\mathrm{N}$ stage compared with the T stage (Table 3). Subgroup analysis based on histotype showed that the TNM stage was not suitable for discriminating patient survival in different histotypes (Table S1).

A survival tree was then built by regrouping tumor histotypes and nodal stages (Figure 1). A new pathological staging system was developed by incorporating groups with similar hazards ratios for survival, and included stages IA (G1N0), IB (G1N1 or G2N0), II (G1N2, G2N1-2, or G3N0) and III (G3N1-2).

In the SEER validation group, patient demographics followed a similar pattern: 2,358 (73.6\%), 259 (8.1\%) and $587(18.3 \%)$ were diagnosed as G1, G2 and G3, respectively; the majority of patients had N0 tumors $(85.3 \%$; $\mathrm{n}=2,732$; Table 1). Kaplan-Meier curves showed a good stratification of survival with 5 -year survival rates of $91.2 \%$, $81.3 \%, 50.2 \%$ and $27.6 \%$ for new stages IA, IB, II and III, respectively $(\mathrm{P}<0.001$, Figure $\mathrm{S} 2)$.

\section{Comparison between the new and TNM staging systems in the SEER and Shanghai cohorts}

In the SEER cohort, the new staging system showed better discrimination for survival than the TNM system (Figure $2 A, B)$. The respective 5 -year survival rates were $91.4 \%$, $81.5 \%, 52.8 \%$ and $29.1 \%$ for stages IA, IB, II, and III according to the new system, respectively $(\mathrm{P}<0.001)$, and $83.7 \%, 86.1 \%, 85.4 \%, 83.5 \%, 82.3 \%, 69.1 \%, 58.5 \%$ and $55.5 \%$ in the TNM staging system, respectively $(\mathrm{P}<0.001)$. In the Cox proportional hazards model (Table 4), the new staging system had significantly better predictive ability compared with the $8^{\text {th }}$ edition of the TNM staging system [C-index: 0.75 (95\% CI: 0.74-0.76) vs. 0.62 (95\% CI: 0.60$0.63)]$. In addition, it enhanced the identification of highrisk patients with an NRI of 0.62 (95\% CI: $0.55-0.68)$ and improved survival prediction with an IDI of $20 \%$ (95\% CI: $18-23 \%)$.

In the Shanghai cohort, patient characteristics were different from those of the SEER cohort [more patients were male $(46.5 \%$ vs. $34.6 \%, \mathrm{P}<0.001)$ and $\mathrm{G} 3$ was the main group (49.2\% vs. $18.3 \%, \mathrm{P}<0.001)$, Table 1]. KaplanMeier curves showed 5 -year survival rates of $98.1 \%, 85.7 \%$, 
Table 1 Characteristics of the patients

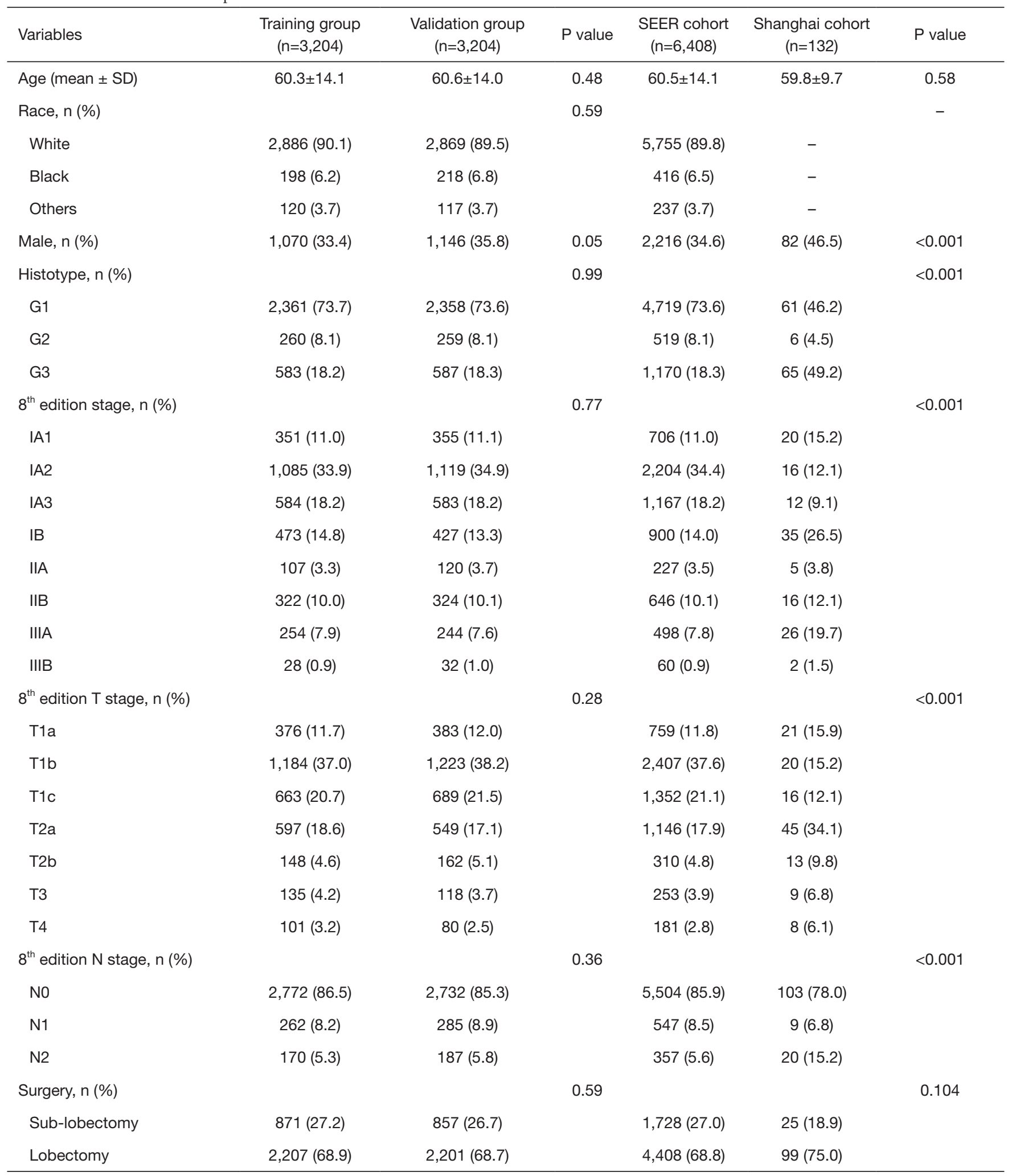

Table 1 (continued) 
Table 1 (continued)

\begin{tabular}{|c|c|c|c|c|c|c|}
\hline Variables & $\begin{array}{l}\text { Training group } \\
\qquad(n=3,204)\end{array}$ & $\begin{array}{l}\text { Validation group } \\
\qquad(n=3,204)\end{array}$ & $P$ value & $\begin{array}{l}\text { SEER cohort } \\
\qquad(\mathrm{n}=6,408)\end{array}$ & $\begin{array}{l}\text { Shanghai cohort } \\
\qquad(n=132)\end{array}$ & $P$ value \\
\hline Pneumonectomy & $114(3.6)$ & $129(4.0)$ & & $243(3.8)$ & $8(6.1)$ & \\
\hline Unknow & $12(0.4)$ & $17(0.5)$ & & $29(0.5)$ & $0(0.0)$ & \\
\hline $\begin{array}{l}\text { Number of regional lymph } \\
\text { nodes removed, } \mathrm{n}(\%)\end{array}$ & & & 0.73 & & & - \\
\hline $1-3$ & $616(19.2)$ & $603(18.8)$ & & $1,219(19.0)$ & - & \\
\hline$>3$ & $1,917(59.8)$ & $1,893(59.1)$ & & $3,810(59.5)$ & - & \\
\hline Unknow & $124(3.9)$ & $130(4.1)$ & & $254(4.0)$ & - & \\
\hline Radiotherapy, n (\%) & & & 0.81 & & & 0.797 \\
\hline Adjuvant & $108(3.4)$ & $106(3.3)$ & & $214(3.3)$ & $8(6.1)$ & \\
\hline Neo- and adjuvant & $2(0.1)$ & $1(0.0)$ & & $3(0.0)$ & $0(0.0)$ & \\
\hline Unknow & $3(0.1)$ & $1(0.0)$ & & $4(0.1)$ & $0(0.0)$ & \\
\hline Adjuvant chemotherapy, n (\%) & & & 0.20 & & & $<0.001$ \\
\hline No & 2,943 (91.9) & $2,914(90.9)$ & & $5,857(91.4)$ & $86(65.2)$ & \\
\hline Yes & $261(8.1)$ & $290(9.1)$ & & $551(8.6)$ & $46(34.8)$ & \\
\hline
\end{tabular}

G1, low-grade typical pulmonary carcinoids; G2 intermediate-grade atypical pulmonary carcinoids; G3, high-grade large cell neuroendocrine carcinomas; SD, standard deviation.

$86.7 \%$ and $40.3 \%$ for stages IA, IB, II and III in the new system, respectively $(\mathrm{P}<0.001)$, and $94.4 \%, 100.0 \%, 90.0 \%$, $100.0 \%, 75.0 \%, 73.8 \%, 50.7 \%$ and $0.0 \%$ in the TNM staging system, respectively $(\mathrm{P}<0.001$, Figure $2 C, D)$. The new staging system improved survival prediction with an IDI of $8 \%$ (95\% CI: $-7 \%$ to $23 \%$, Table 4 ) relative to the TNM staging system.

\section{Value of the new staging system in the use of adjuvant chemotherapy}

There were 46 patients $(n=132,34.8 \%)$ administered adjuvant chemotherapy [platinum combined with paclitaxel (10.9\%), gemcitabine (13.0\%), pemetrexed $(23.9 \%)$, etoposide $(23.9 \%)$, or other $(28.3 \%)]$ in the Shanghai cohort, versus $551(\mathrm{n}=6,408,8.6 \%)$ in the SEER cohort. Kaplan-Meier curves showed that adjuvant chemotherapy was associated with improved survival in new stage III cases, and worse survival in new stage IA-II cases (Figure 3). In the Shanghai cohort, median survival was prolonged in the adjuvant chemotherapy group with new stage III tumors (26 vs. 22 months, $\mathrm{P}=0.69$, Figure 4), but no survival benefit of chemotherapy was found for various TNM stages (Figures S3,S4). In subgroup analysis, adjuvant chemotherapy provided a significant survival benefit in G3 (HR $=0.61,95 \% \mathrm{CI}: 0.46-0.75)$, but decreased survival in G1 $(\mathrm{HR}=1.37,95 \% \mathrm{CI}: 0.69-2.71)$ and G2 (HR =0.68, 95\% CI: 0.34-1.35; Figure 5A). The $\mathrm{P}$ value for interaction was 0.11 . However, a role for adjuvant chemotherapy was not observed in any $\mathrm{T}$ stage ( $\mathrm{P}$ for interaction $=0.52$ ). Besides, by subgroup analysis of both staging systems, chemotherapy provided significant survival benefit in new stage III cases (HR =0.34, 95\% CI: $0.25-0.45$ ), and survival benefit differed among various new stage-based subgroups significantly (P for interaction $<0.001$, Figure $5 B$ ).

\section{Discussion}

In this large-sample retrospective study of NETL, we explored factors associated with prognosis in patients with 
Table 2 Univariate, multivariate Cox regression analysis and random forest model on factors influencing survival in the training group

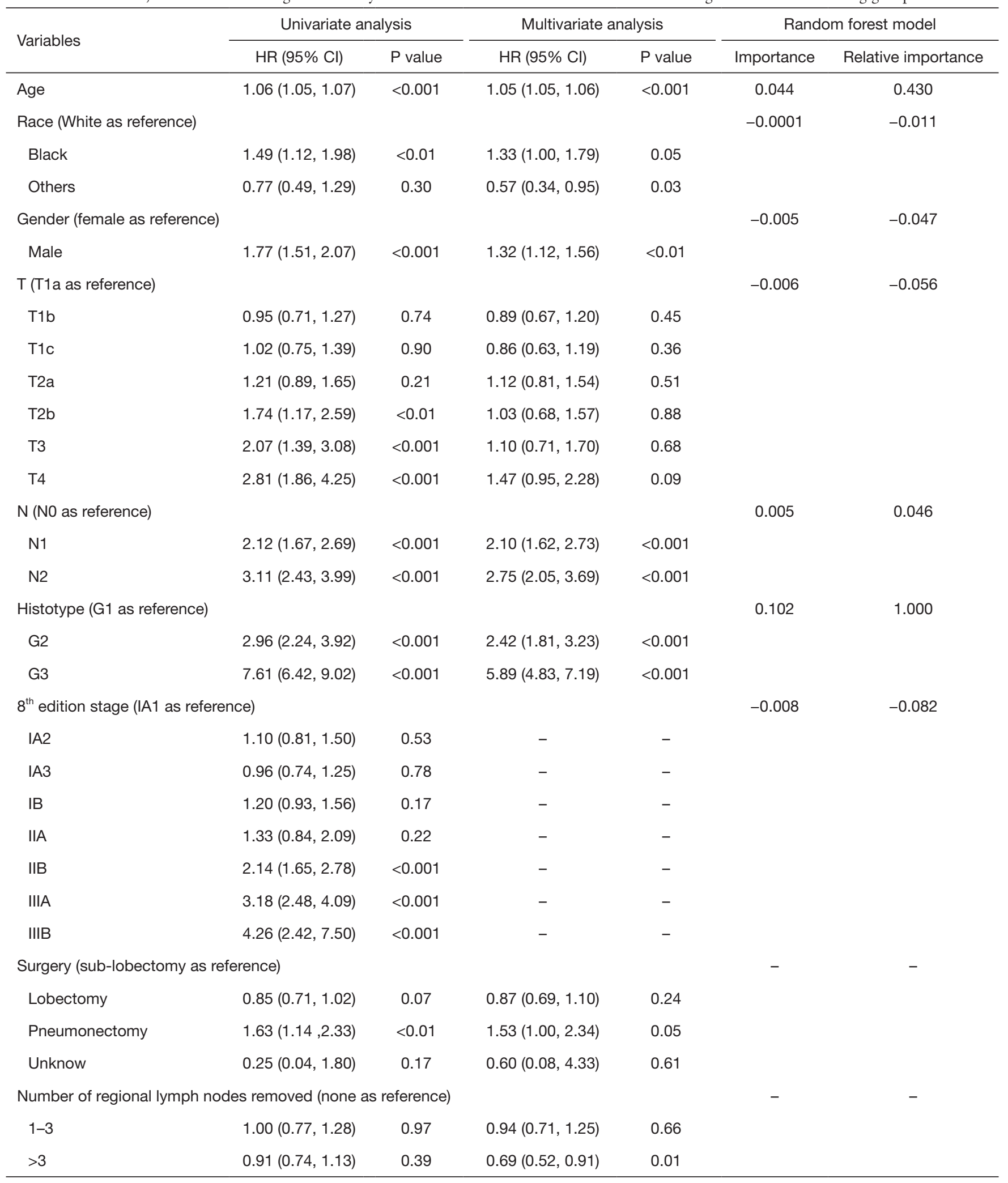

Table 2 (continued) 
Table 2 (continued)

\begin{tabular}{|c|c|c|c|c|c|c|}
\hline Variables & \multicolumn{2}{|c|}{ Univariate analysis } & \multicolumn{2}{|c|}{ Multivariate analysis } & \multicolumn{2}{|c|}{ Random forest model } \\
\hline Unknow & $0.99(0.66,1.49)$ & 0.95 & $0.59(0.38,0.91)$ & 0.02 & & \\
\hline \multicolumn{7}{|c|}{ Radiotherapy (no as reference) } \\
\hline Neoadjuvant & $\begin{array}{c}0.00(0.00 \\
1.532 \mathrm{E}+052)\end{array}$ & 0.89 & & & & \\
\hline \multicolumn{7}{|c|}{ Neo- and adjuvant } \\
\hline & $8.62(1.21,61.37)$ & 0.03 & & & & \\
\hline Unknow & $\begin{array}{c}0.00(0.00 \\
1.644 \mathrm{E}+185)\end{array}$ & 0.97 & & & & \\
\hline
\end{tabular}

G1, low-grade typical pulmonary carcinoids; G2 intermediate-grade atypical pulmonary carcinoids; G3, high-grade large cell neuroendocrine carcinomas.

NETL. NETL histotype had a better survival predictive ability than the $T$ stage. Therefore, we developed a new pathological staging system based on histotype and nodal status for NETL, which showed a better discriminative ability in the SEER and Shanghai cohorts. In addition, the new system had the potential to identify patients suitable for adjuvant chemotherapy, while the benefit conferred by adjuvant chemotherapy was not associated with the TNM stage.

The importance of specific staging systems for NETL has been realized recently. Several reports have shown an overlapping survival of patients with NETL in stages I and II $(11,12)$. Tumor histotype and differentiation are crucial determinants of the clinical behavior of NETL. Corroborating a study by Skuladottir et al. (13), we found that NETL histotype was a significant prognostic factor of NETL. As for the $\mathrm{N}$ stage, many studies have pointed out that nodal invasion obviously influences NETL prognosis and is related to poor outcome $(12,14,15)$. In line with these previous findings, the present study showed that nodal stage still had the potential to predict prognosis and constituted an independent factor for patient survival.

Conversely, the $8^{\text {th }}$ edition of the $T$ staging system had a weak discriminative ability in the prognosis of patients with NETL in this study. A single-center trial also pointed out that the $\mathrm{T}$ stage is not independently associated with survival in NETL (16). Aly et al. (17) found that tumor size (per 1 centimeter increase) is not associated with recurrence $(\mathrm{HR}=1.09,95 \% \mathrm{CI}$ : $0.97-1.22 ; \mathrm{P}=0.20$ ) or lung cancer-specific death (HR $=1.11,95 \% \mathrm{CI}$ : 0.98-1.26; $\mathrm{P}=0.10$ ).

Although Jackson et al. (6) explored a staging system for NETL including histotype, N- and T-stage, there was no significant improvement in its ability of prognostic discrimination compared to the new staging system developed in this work (NRI $=0.03,95 \% \mathrm{CI}:<-0.01$ to 0.38 ; IDI $=-0.6 \%, 95 \%$ CI: $-1.7 \%$ to $0.7 \%$; Table S2). This supported our results that the $\mathrm{T}$ stage had no good prognostic discrimination in NETL. Moreover, histotype showed a good survival discrimination in non-surgical patients, while T-stage did not (Figure S5). Given the practicality of the staging system, it is reasonable to replace the T stage with NETL histotype.

The pathological stage is important not only for predicting prognosis but also for advising postoperative treatment. However, there is no consensus regarding adjuvant therapy in NETL. For large-cell neuroendocrine carcinomas, adjuvant chemotherapy after surgery appears promising for the improvement of prognosis (18). In this study, adjuvant chemotherapy showed no survival benefit in various TNM stages, but the new system could select appropriate patients (new stage III) who might achieve survival benefit after adjuvant chemotherapy. Moreover, by subgroup analysis, we observed no association of 
Table 3 Multivariate Cox regression analysis to compare histotype and $\mathrm{T}$ stage by subgroup analysis of $\mathrm{N}$ stage, adjusted by race, gender, age, surgery, number of regional lymph nodes removed and adjuvant chemotherapy

\begin{tabular}{|c|c|c|}
\hline Variables & $\mathrm{HR}(95 \% \mathrm{Cl})$ & $P$ value \\
\hline \multicolumn{3}{|l|}{ NO } \\
\hline \multicolumn{3}{|c|}{ G1 as reference } \\
\hline G2 & $2.45(1.71,3.51)$ & $<0.001$ \\
\hline G3 & $6.14(4.95,7.62)$ & $<0.001$ \\
\hline \multicolumn{3}{|c|}{$\mathrm{T} 1$ as reference } \\
\hline $\mathrm{T} 2$ & $1.30(1.03,1.64)$ & 0.03 \\
\hline T3 & $1.67(1.08,2.58)$ & 0.02 \\
\hline $\mathrm{T} 4$ & $1.36(0.85,2.18)$ & 0.20 \\
\hline \multicolumn{3}{|l|}{$\mathrm{N} 1$} \\
\hline \multicolumn{3}{|c|}{$\mathrm{G} 1$ as reference } \\
\hline G2 & $3.01(1.40,6.46)$ & $<0.01$ \\
\hline G3 & $10.66(5.21,21.79)$ & $<0.001$ \\
\hline \multicolumn{3}{|c|}{ T1 as reference } \\
\hline $\mathrm{T} 2$ & $1.24(0.72,2.15)$ & 0.43 \\
\hline T3 & $0.54(0.20,1.44)$ & 0.22 \\
\hline $\mathrm{T} 4$ & $1.38(0.58,3.29)$ & 0.47 \\
\hline \multicolumn{3}{|l|}{ N2 } \\
\hline \multicolumn{3}{|c|}{ G1 as reference } \\
\hline G2 & $1.54(0.75,3.18)$ & 0.24 \\
\hline G3 & $6.10(2.42,15.35)$ & $<0.01$ \\
\hline \multicolumn{3}{|c|}{$\mathrm{T} 1$ as reference } \\
\hline $\mathrm{T} 2$ & $0.87(0.49,1.53)$ & 0.62 \\
\hline T3 & $0.96(0.40,2.31)$ & 0.93 \\
\hline $\mathrm{T} 4$ & $2.57(0.96,6.83)$ & 0.06 \\
\hline
\end{tabular}

G1, low-grade typical pulmonary carcinoids; G2 intermediategrade atypical pulmonary carcinoids; G3, high-grade large cell neuroendocrine carcinomas. chemotherapy effect with T stage; however, survival advantage was noted in G3 patients administered adjuvant chemotherapy. Taken together, replacing the $\mathrm{T}$ stage with histotype may help redefine prognostication and would have great potential for advising postoperative treatment in patients with these tumors.

The limitations of the current study include its retrospective nature, with the inherent trend of selection bias. Secondly, detailed data about diaphragm invasion, positive margins, mitotic rate and $\mathrm{Ki}-67$ were not recorded in the SEER database, all of which are reportedly associated with survival. Furthermore, this study only included M0 postoperative patients. Therefore, the proposed staging system needs to be explored for stage N3 or M1 patients with NETL. Finally, even though the new staging system has been verified in the Shanghai cohort, the lack of data (especially for G2 patients, adjuvant chemotherapy and hormonal or targeted therapy) and the effect of different eras (2004-2015 and 2009-2018 for the SEER and Shanghai cohorts, respectively), which has implications on the variation of diagnostic and therapeutic options available, could cause bias. Therefore, the new staging system for NETL still needs more external validation and detailed data in an independent cohort before its clinical application.

In conclusion, NETL constitute a unique clinical subgroup of primary lung tumors. However, there is no specific pathological staging system for these tumors. This study found that tumor histotype and nodal status were independently associated with survival in NETL patients, rather than the $\mathrm{T}$ stage. Therefore, we established a new pathological staging system for postoperative patients by combining NETL histotype and nodal stage, which was validated in the Shanghai cohort. The new pathological staging system could predict the prognosis of NETL patients better than the $8^{\text {th }}$ TNM staging system, and also has the potential to guide postoperative chemotherapy. 


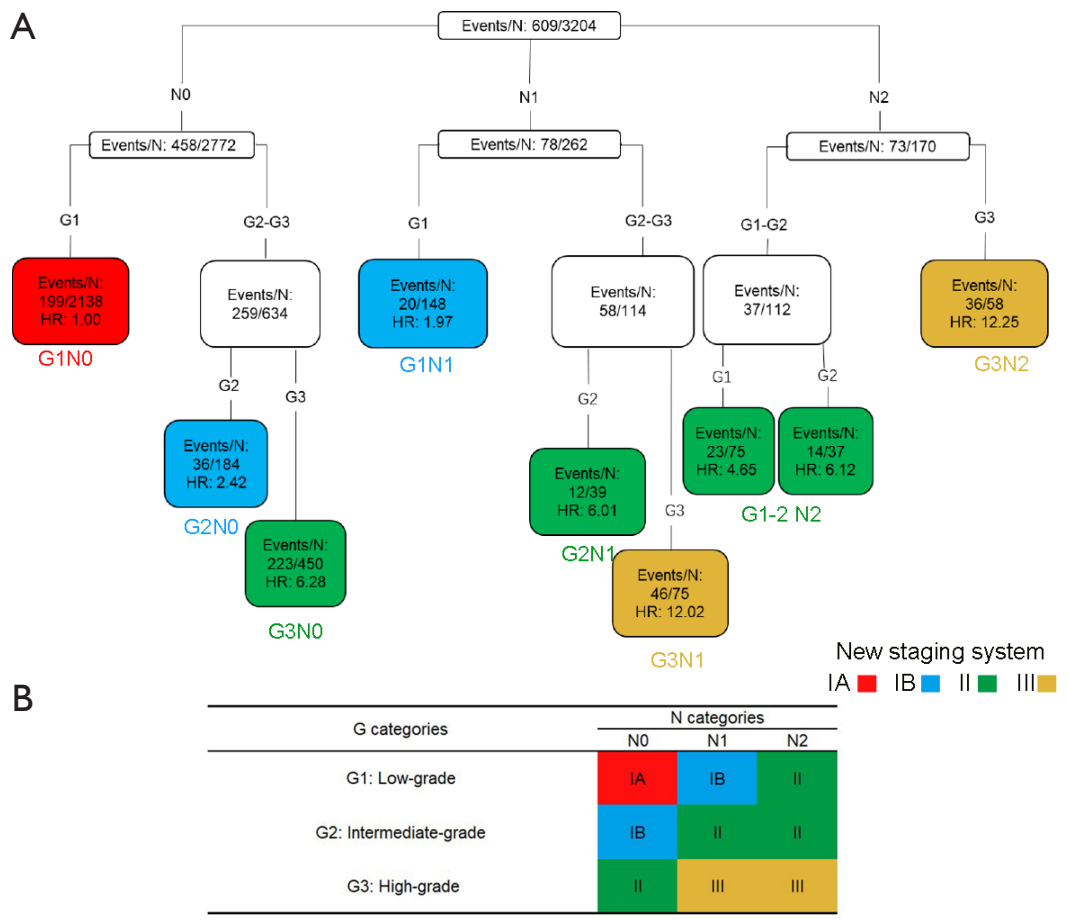

Figure 1 New staging system proposed by the survival tree. (A) Survival tree based on the best stage for 3,224 M0 resected cases in the training group. Histotype and $\mathrm{N}$ categories were modeled as ordered variables. (B) The new staging system proposed by regrouping $\mathrm{G}$ and $\mathrm{N}$ stages based on hazards ratios (HRs).
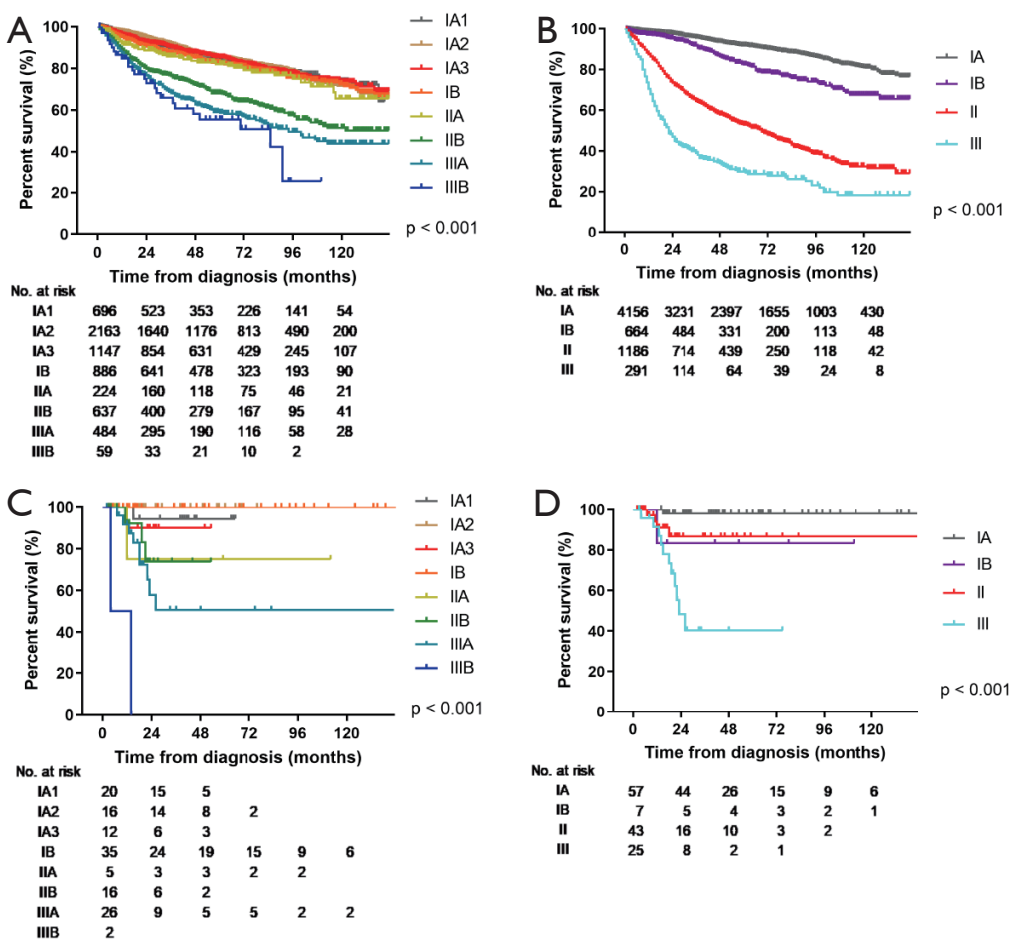

Figure 2 Overall survival by pathologic stage. (A) TNM stage in the SEER cohort; (B) new stage in the SEER cohort; (C) TNM stage in the Shanghai cohort; (D) new stage in the Shanghai cohort. 
Table 4 Comparison of univariate Cox regression analysis and survival prediction ability for the $8^{\text {th }}$ edition TNM stage and new stage

\begin{tabular}{|c|c|c|c|c|c|c|c|}
\hline Stage & \multicolumn{2}{|c|}{$8^{\text {th }} \mathrm{Ed}$. } & Stage & \multicolumn{2}{|c|}{ New-Ed. } & \multicolumn{2}{|c|}{ New-Ed. vs. $8^{\text {th }}$ Ed. } \\
\hline \multicolumn{8}{|l|}{ SEER cohort } \\
\hline $\begin{array}{l}\text { IA1 as } \\
\text { reference }\end{array}$ & & $\begin{array}{c}0.62(0.60 \\
0.63)\end{array}$ & IA as reference & & $0.75(0.74,0.76)$ & $0.62(0.55,0.68)$ & $20(18,23)^{\star \star \star}$ \\
\hline IB & $1.20(0.93,1.56)$ & & 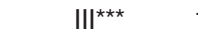 & $12.63(10.63,15.00)$ & & & \\
\hline IIA & $\begin{array}{c}1.33(0.84 \\
2.09)\end{array}$ & & & & & & \\
\hline $\mathrm{IIB}^{\star \star \star}$ & $\begin{array}{c}2.14(1.65 \\
2.78)\end{array}$ & & & & & & \\
\hline$I I I B^{\star \star \star}$ & $\begin{array}{c}4.26(2.42 \\
7.50)\end{array}$ & & & & & & \\
\hline \multicolumn{8}{|c|}{ Shanghai cohort } \\
\hline $\begin{array}{l}\text { IA1 as } \\
\text { reference }\end{array}$ & & $-^{\dagger}$ & IA as reference & & $0.80(0.71,0.88)$ & $0.0048^{\ddagger}$ & $8(-7,23)$ \\
\hline IA2 & $\begin{array}{c}0.00(0.00 \\
3.038 E+219)\end{array}$ & & IB & $10.73(0.67,171.52)$ & & & \\
\hline IA3 & $2.11(0.13,33.80)$ & & II & $8.36(0.93,75.03)$ & & & \\
\hline$I I I A^{*}$ & $\begin{array}{c}9.27(1.17 \\
73.53)\end{array}$ & & & & & & \\
\hline $\mathrm{IIIB}^{\star \star *}$ & $\begin{array}{c}99.67 \text { (8.15 } \\
1,219.39)\end{array}$ & & & & & & \\
\hline
\end{tabular}

IDI, integrated discrimination improvement; NRI, net reclassification index. ${ }^{*}, \mathrm{P}<0.05 ;{ }^{* \star *}, \mathrm{P}<0.001 .{ }^{\dagger}$, coefficient may be infinite in the cox model due to little outcome events which may cause data bias; ${ }^{\ddagger}$, cox model can't be established due to little outcome events for which 95\% Cl can't be analyzed by bootstrapping. 

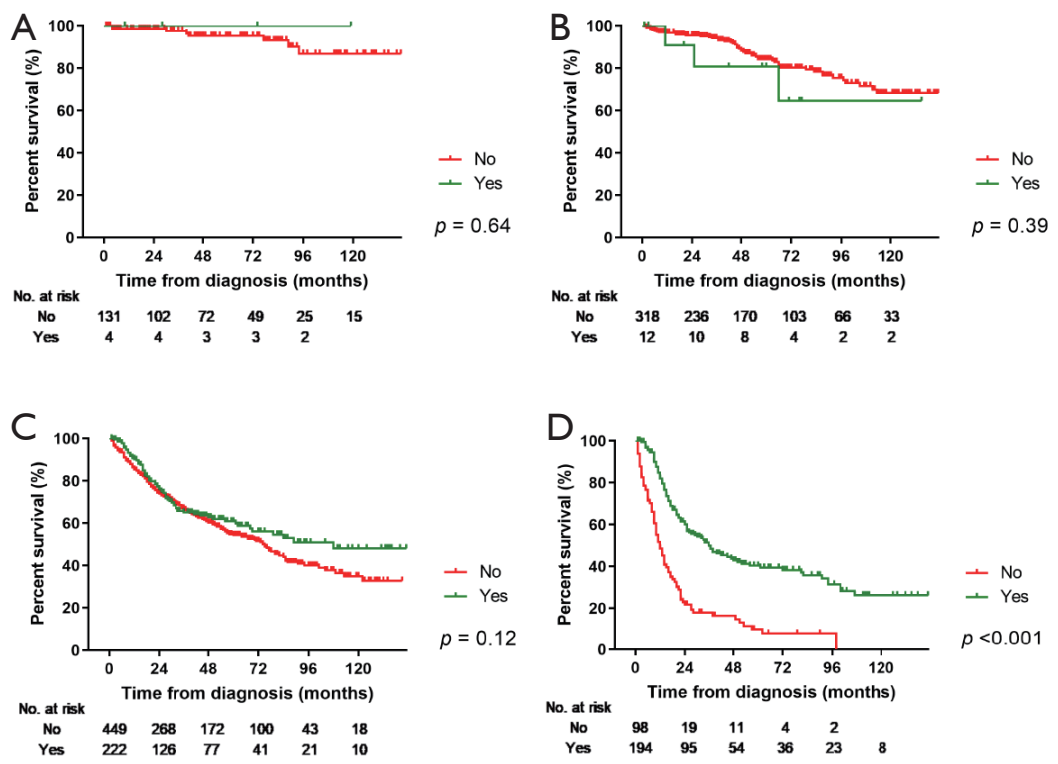

Figure 3 Overall survival by adjuvant chemotherapy according to the new staging system. (A) Stage IA, (B) stage IB, (C) stage II, and (D) stage III in the SEER cohort.
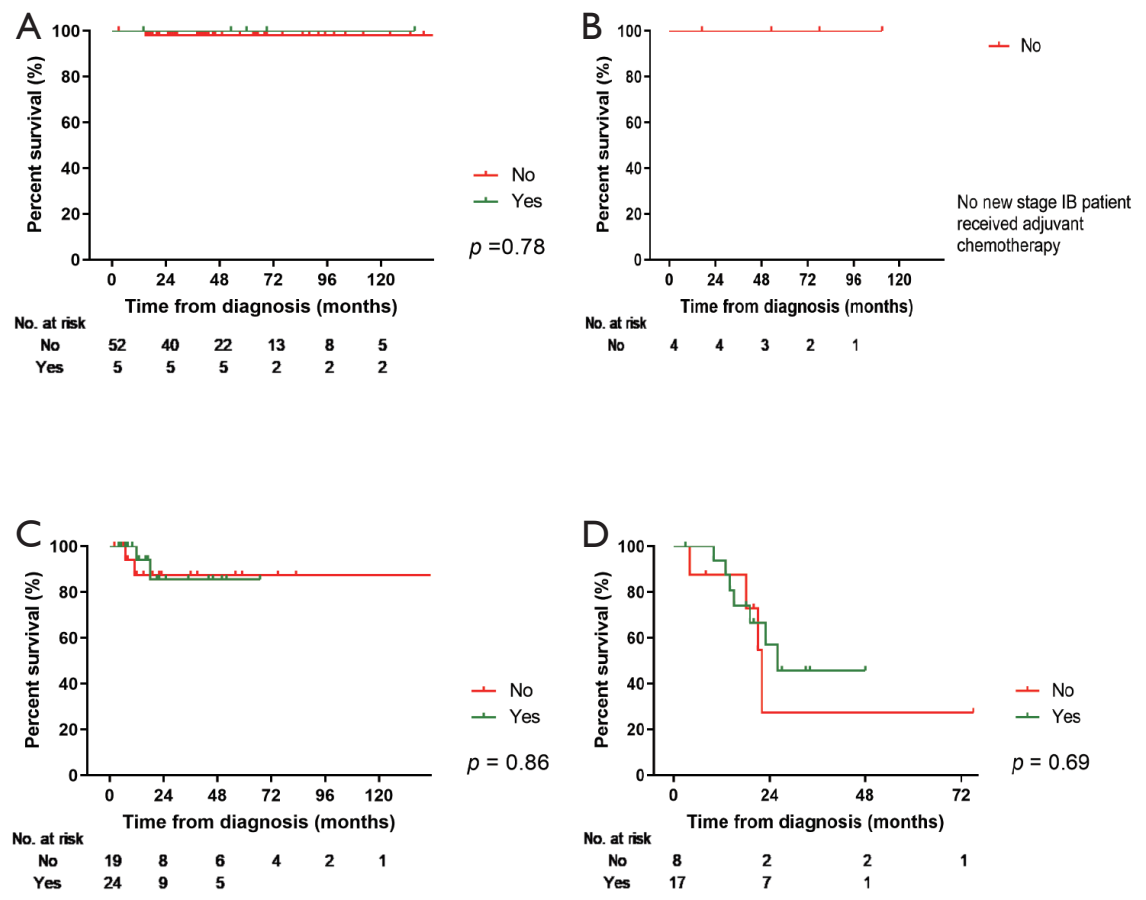

Figure 4 Overall survival by adjuvant chemotherapy according to the new staging system. (A) Stage IA, (B) stage IB, (C) stage II, and (D) stage III in the Shanghai cohort. 


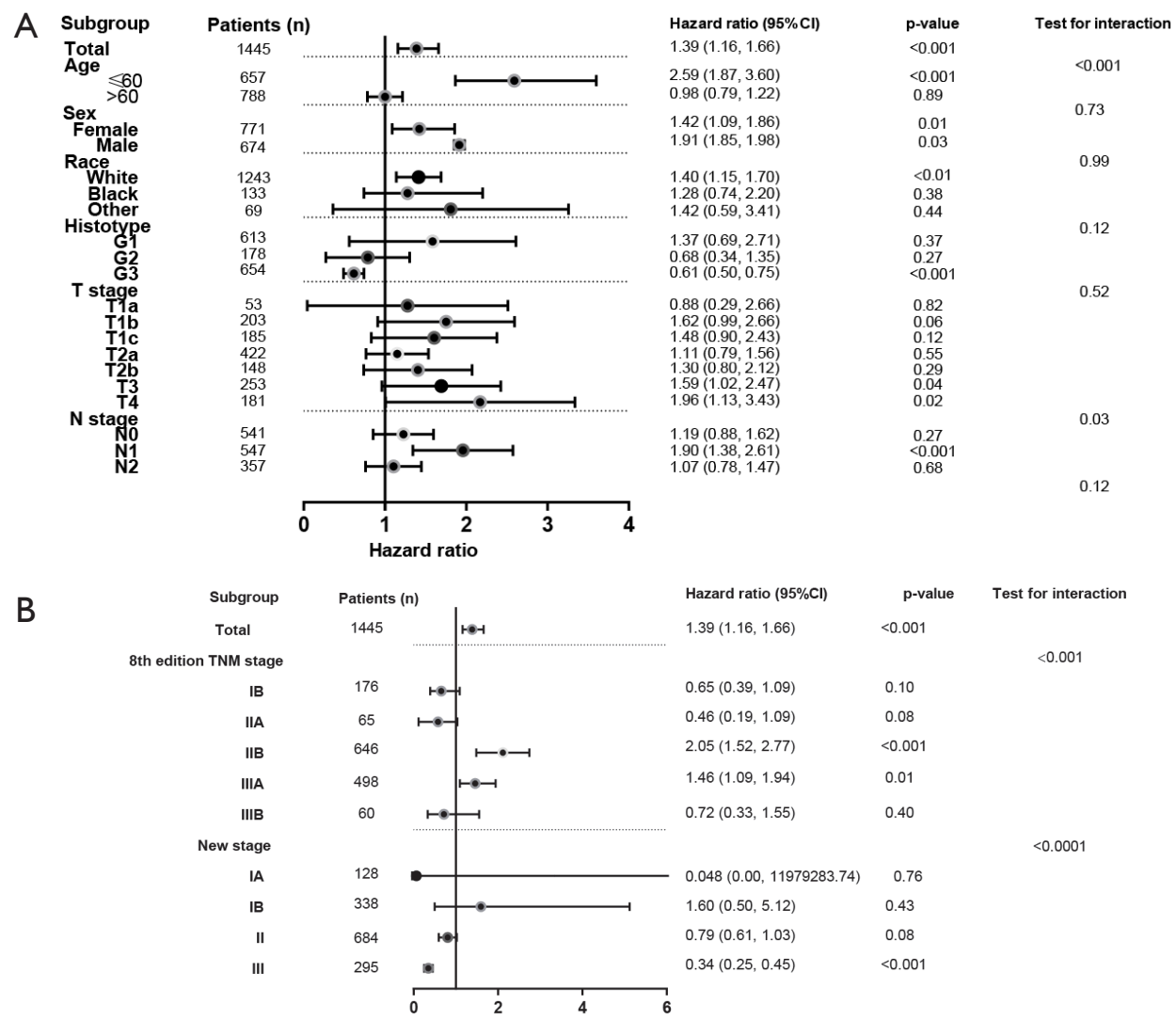

Figure 5 Subgroup analysis for adjuvant chemotherapy (adjuvant chemotherapy as reference). (A) Subgroups based on baseline characteristics; (B) subgroups based on staging systems.

\section{Acknowledgments}

Funding: This work was supported by the National Natural Science Foundation of China (Grant No. 81972172, 81802260), Program of Shanghai Academic Research Leader (Grant No. 19XD1423200), the Shanghai Science and Technology Committee (Grant No. 18140903900), Shanghai Rising-Star Program (No. 19QA1407400), the Shanghai Hospital Development Center (Grant No. SHDC12018122, SHDC2020CR2020B).

\section{Footnote}

Reporting Checklist: The authors have completed the STROBE reporting checklist. Available at http://dx.doi. org/10.21037/atm-20-5910

Peer Review File: Available at http://dx.doi.org/10.21037/ atm-20-5910

Conflicts of Interest: All authors have completed the ICMJE uniform disclosure form (available at: http://dx.doi. org/10.21037/atm-20-5910). The authors have no conflicts of interest to declare.

Ethical Statement: The authors are accountable for all aspects of the work in ensuring that questions related to the accuracy or integrity of any part of the work are appropriately investigated and resolved. The study was conducted in accordance with the Declaration of Helsinki (as revised in 2013).

Open Access Statement: This is an Open Access article distributed in accordance with the Creative Commons Attribution-NonCommercial-NoDerivs 4.0 International License (CC BY-NC-ND 4.0), which permits the non- 
commercial replication and distribution of the article with the strict proviso that no changes or edits are made and the original work is properly cited (including links to both the formal publication through the relevant DOI and the license). See: https://creativecommons.org/licenses/by-nc-nd/4.0/.

\section{References}

1. Travis WD, Brambilla E, Nicholson AG, et al. The 2015 world health organization classification of lung tumors: Impact of genetic, clinical and radiologic advances since the 2004 classification. J Thorac Oncol 2015;10:1243-60.

2. Yao JC, Hassan M, Phan A, et al. One hundred years after "carcinoid": epidemiology of and prognostic factors for neuroendocrine tumors in 35,825 cases in the United States. J Clin Oncol 2008;26:3063-72.

3. Dasari A, Shen C, Halperin D, et al. Trends in the Incidence, Prevalence, and Survival Outcomes in Patients With Neuroendocrine Tumors in the United States. JAMA Oncol 2017;3:1335-42.

4. Mountain CF. Staging classification of lung cancer. A critical evaluation. Clin Chest Med 2002;23:103-21.

5. Rami-Porta R, Asamura $\mathrm{H}$, Travis WD, et al. Lung cancer - major changes in the american joint committee on cancer eighth edition cancer staging manual. CA Cancer J Clin 2017;67:138-55.

6. Jackson AS, Rosenthal A, Cattoni M, et al. Staging system for neuroendocrine tumors of the lung needs to incorporate histologic grade. Ann Thorac Surg 2020;109:1009-18.

7. Volante M, Gatti G, Papotti M. Classification of lung neuroendocrine tumors: Lights and shadows. Endocrine 2015;50:315-9.

8. National Comprehensive Cancer Network Clinical Practice Guidelines in Oncology. Non-Small Cell Lung Cancer (Version 4.2020). Available online: https:// www.nccn.org/professionals/physician_gls/pdf/nscl.pdf. Accessed May 25,2020.

Cite this article as: Yi C, Dai J, Song N, Wu C, Zhang L, Zhu Y, Jiang G, Zhang H, Zhang P. Improvement of pathological staging system for neuroendocrine tumors of the lung. Ann Transl Med 2021;9(6):447. doi: 10.21037/atm-20-5910
9. Pencina MJ, D'Agostino RB Sr, Steyerberg EW. Extensions of net reclassification improvement calculations to measure usefulness of new biomarkers. Stat Med 2011;30:11-21.

10. Chambless LE, Cummiskey CP, Cui G. Several methods to assess improvement in risk prediction models: Extension to survival analysis. Stat Med 2011;30:22-38.

11. Aydin E, Yazici U, Gulgosteren M, et al. Long-term outcomes and prognostic factors of patients with surgically treated pulmonary carcinoid: our institutional experience with 104 patients. Eur J Cardiothorac Surg 2011;39:549-54.

12. Filosso PL, Oliaro A, Ruffini E, et al. Outcome and prognostic factors in bronchial carcinoids: a single-center experience. J Thorac Oncol 2013;8:1282-8.

13. Skuladottir H, Hirsch FR, Hansen HH, et al. Pulmonary neuroendocrine tumors: incidence and prognosis of histological subtypes. A population-based study in Denmark. Lung Cancer 2002;37:127-35.

14. Canizares MA, Matilla JM, Cueto A, et al. Atypical carcinoid tumours of the lung: prognostic factors and patterns of recurrence. Thorax 2014;69:648-53.

15. Eichhorn F, Dienemann H, Muley T, et al. Predictors of Survival After Operation Among Patients With Large Cell Neuroendocrine Carcinoma of the Lung. Ann Thorac Surg 2015;99:983-9.

16. Filosso PL, Ruffini E, Di Gangi S, et al. Prognostic factors in neuroendocrine tumours of the lung: a single-centre experience. Eur J Cardiothorac Surg 2014;45:521-6; discussion 6.

17. Aly RG, Rekhtman N, Li X, et al. Spread Through Air Spaces (STAS) Is Prognostic in Atypical Carcinoid, Large Cell Neuroendocrine Carcinoma, and Small Cell Carcinoma of the Lung. J Thorac Oncol 2019;14:1583-93.

18. Iyoda A, Hiroshima K, Moriya Y, et al. Prospective study of adjuvant chemotherapy for pulmonary large cell neuroendocrine carcinoma. Ann Thorac Surg 2006;82:1802-7. 


\section{Supplementary}

Table S1 Univariate and multivariate Cox regression analysis for $8^{\text {th }}$ edition TNM stage by stratified analysis of histotype, adjusted by race, gender, age, surgery, number of regional lymph nodes removed, radiotherapy and adjuvant chemotherapy

\begin{tabular}{lllll}
\hline \multirow{2}{*}{ Variables } & \multicolumn{2}{c}{ Univariate analysis } & Variables & Multivariate analysis \\
\cline { 2 - 3 } & $\mathrm{HR}(95 \% \mathrm{Cl})$ & $\mathrm{P}$ value & $\mathrm{HR}(95 \% \mathrm{Cl})$ & $\mathrm{P}$ value \\
\hline
\end{tabular}

\section{G1}

IA1 as reference

IA2
IA3
IIA
IIB
IIIA

G2

$\mathrm{G} 1$ as reference

IB

IIA

IIB

IIIA

IIIB

G3

IA1 as reference

$\begin{array}{ll}\text { IA2 } & 0.97(0.56,1.71) \\ \text { IA3 } & 1.20(0.68,2.14) \\ \text { IB } & 1.03(0.57,1.86) \\ \text { IIA } & 0.78(0.36,1.69) \\ \text { IIB } & 1.62(0.92,2.85) \\ \text { IIIA } & 1.52(0.87,2.66) \\ \text { IIIB } & 2.11(0.86,5.18)\end{array}$

IA2

$1.57(0.46,5.33)$

$0.75(0.19,2.92)$

$0.80(0.20,3.20)$

$0.00(0.00,1.471 \mathrm{E}+262$

$1.70(0.47,6.10)$

$1.87(0.54,6.52)$

$3.30(0.55,19.85)$

$2.11(0.86,5.18)$

$\begin{array}{ll}0.04 & \text { IA2 } \\ <0.01 & \text { IA3 } \\ 0.27 & \text { IB } \\ 0.97 & \text { IIA } \\ 0.83 & \text { IIB } \\ 0.05 & \text { IIIA } \\ 0.06 & \text { IIIB }\end{array}$

IA1 as reference

$$
0.74(0.50,1.11)
$$

0.14

$0.53(0.32,0.89)$

0.01

$1.25(0.78,2.01)$

0.36

$1.60(0.78,3.28)$

0.20

$1.51(0.86,2.64)$

0.15

2.23(1.27, 3.91)

0.01

2.36(0.72, 7.72)

0.16

$\mathrm{T} 1$ as reference

$\begin{array}{ll}0.47 & \text { IA2 } \\ 0.68 & \text { IA3 } \\ 0.75 & \text { IB } \\ 0.97 & \text { IIA } \\ 0.42 & \text { IIB } \\ 0.33 & \text { IIIA } \\ 0.19 & \text { IIIB }\end{array}$

$$
0.99(0.26,3.80)
$$

0.98

$0.51(0.12,2.22)$

0.37

0.72(0.16, 3.18)

0.67

0.00(0.00, 2.042E+278)

0.97

2.07(0.55, 7.88)

0.28

$2.16(0.53,8.74)$

0.28

$3.76(0.49,28.77)$

0.20

$\mathrm{T} 1$ as reference

G1, low-grade typical pulmonary carcinoids; G2 intermediate-grade atypical pulmonary carcinoids; G3, high-grade large cell neuroendocrine carcinomas. 
Table S2 Comparison of univariate Cox regression analysis and survival prediction ability for the already published classification and new stage

\begin{tabular}{|c|c|c|c|c|c|c|c|}
\hline \multirow{2}{*}{ Stage } & \multicolumn{2}{|c|}{ Already published classification } & \multirow{2}{*}{ Stage } & \multicolumn{2}{|c|}{ New-Ed. } & \multicolumn{2}{|c|}{$\begin{array}{l}\text { New-Ed. vs already published } \\
\text { classification }\end{array}$} \\
\hline & $\mathrm{HR}(95 \% \mathrm{Cl})$ & $\begin{array}{l}\text { C-index } \\
(95 \% \mathrm{Cl})\end{array}$ & & $\mathrm{HR}(95 \% \mathrm{Cl})$ & C-index $(95 \% \mathrm{Cl})$ & $\mathrm{NRI}(95 \% \mathrm{Cl})$ & IDI(\%,95\%CI) \\
\hline \multicolumn{8}{|l|}{ SEER cohort } \\
\hline IA as reference & & $\begin{array}{c}0.75 \\
(0.73,0.76)\end{array}$ & $\begin{array}{l}\mathrm{IA} \text { as } \\
\text { reference }\end{array}$ & & $0.75(0.74,0.76)$ & $\begin{array}{c}0.03(<-0.01 \\
0.38)\end{array}$ & $-0.6(-1.7,0.7)$ \\
\hline $\mathrm{IB}^{\star \star \star}$ & $2.09(1.56,2.81)$ & & $\mathrm{IB}^{\star \star \star}$ & $1.99(1.62,2.45)$ & & & \\
\hline$\| A^{\star \star \star}$ & $2.05(1.58,2.67)$ & & $I^{\star \star \star}$ & $6.53(5.74,7.42)$ & & & \\
\hline$\| \mathrm{B}^{\star \star \star}$ & $4.29(3.17,5.79)$ & & $\| I^{\star \star \star}$ & $12.74(10.72,15.15)$ & & & \\
\hline$\| I I A^{\star \star \star}$ & $7.06(6.18,8.06)$ & & & & & & \\
\hline \multicolumn{8}{|l|}{ Shanghai cohort } \\
\hline IA as reference & & $-{ }^{a}$ & $\begin{array}{l}\mathrm{IA} \text { as } \\
\text { reference }\end{array}$ & & $0.80(0.71,0.88)$ & $-0.1^{3} \mathrm{~b}$ & $-1.7(-14.2,1.4)$ \\
\hline IB & $0.00(0.00,-7.98 \mathrm{E}+307)$ & & IB & $10.73(0.67,171.52)$ & & & \\
\hline$\| A$ & $13.20(0.83,211.22)$ & & II & $8.36(0.93,75.03$ & & & \\
\hline$\| B^{c}$ & & & $\| I^{\star \star \star}$ & $35.18(4.51,274.20)$ & & & \\
\hline IIIA & $5.76(0.52,63.64)$ & & & & & & \\
\hline$I I I B^{\star *}$ & $36.97(3.30,414.47)$ & & & & & & \\
\hline
\end{tabular}

IDI, integrated discrimination improvement; NRI, net reclassification index. ${ }^{*}, p<0.05 ;{ }^{* *}, p<0.01 ;{ }^{* *}, p<0.001$. $^{\text {a }}$, coefficient may be infinite in the cox model due to little outcome events which may cause data bias; ${ }^{b}$, cox model can't be established due to little outcome events for which $95 \% \mathrm{Cl}$ can't be analyzed by bootstrapping; ${ }^{\mathrm{c}}$, no patients in the already published classification stage IIB in the Shanghai cohort. 


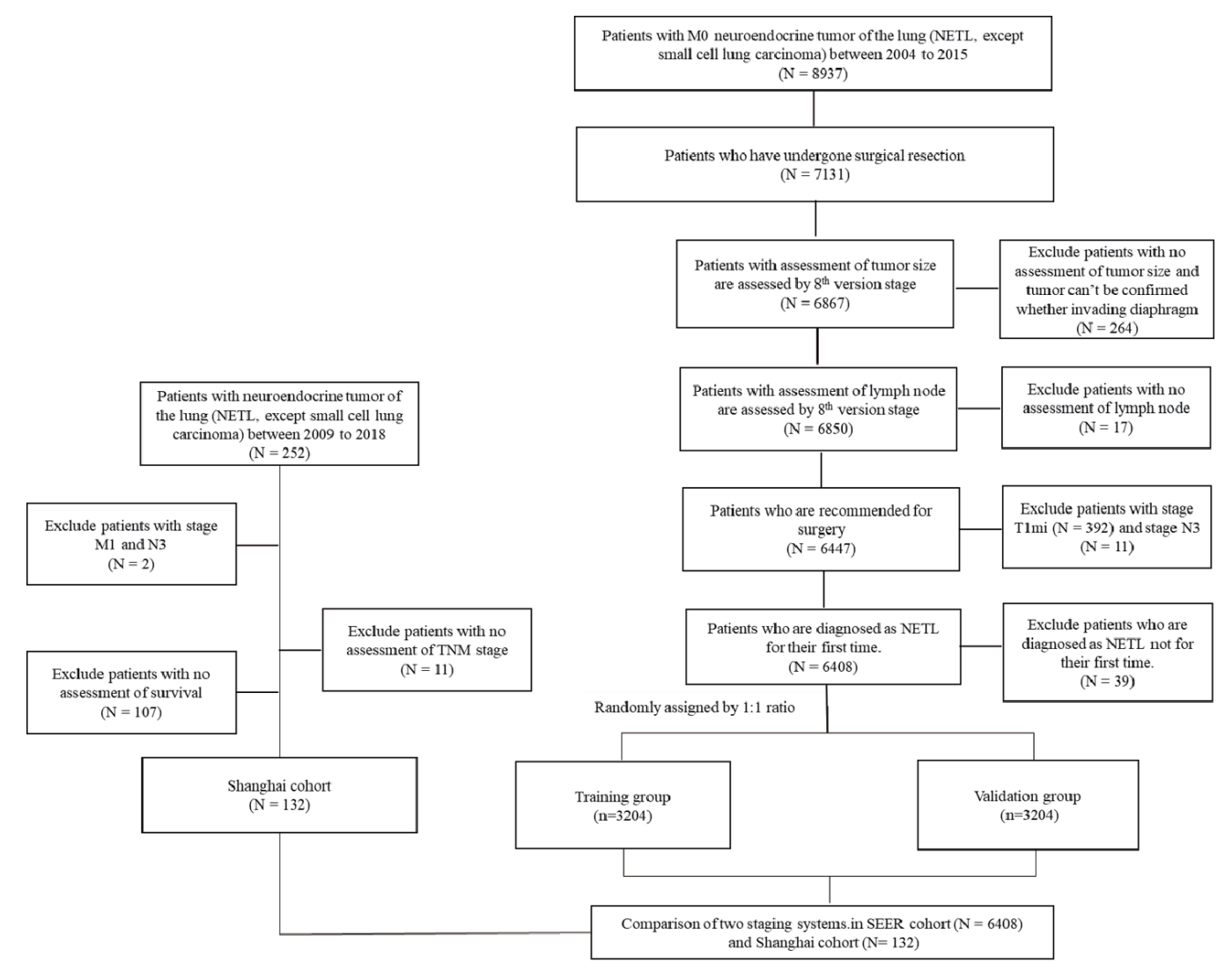

Figure S1 Flow chart depicting selection criteria and grouping steps.

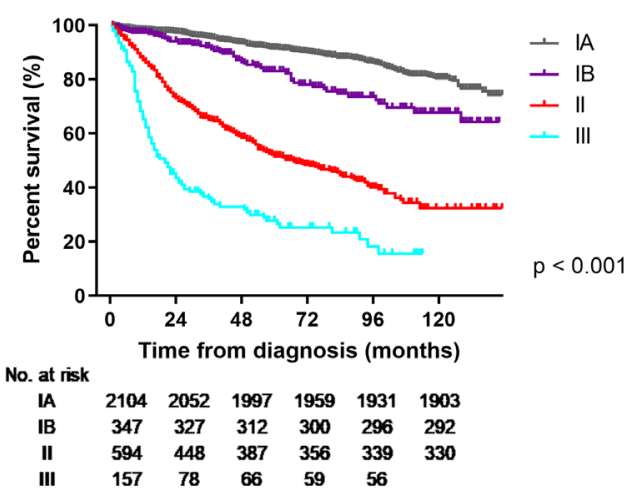

Figure S2 Overall survival by pathologic stage according to the new pathological staging system in the SEER validation group. 

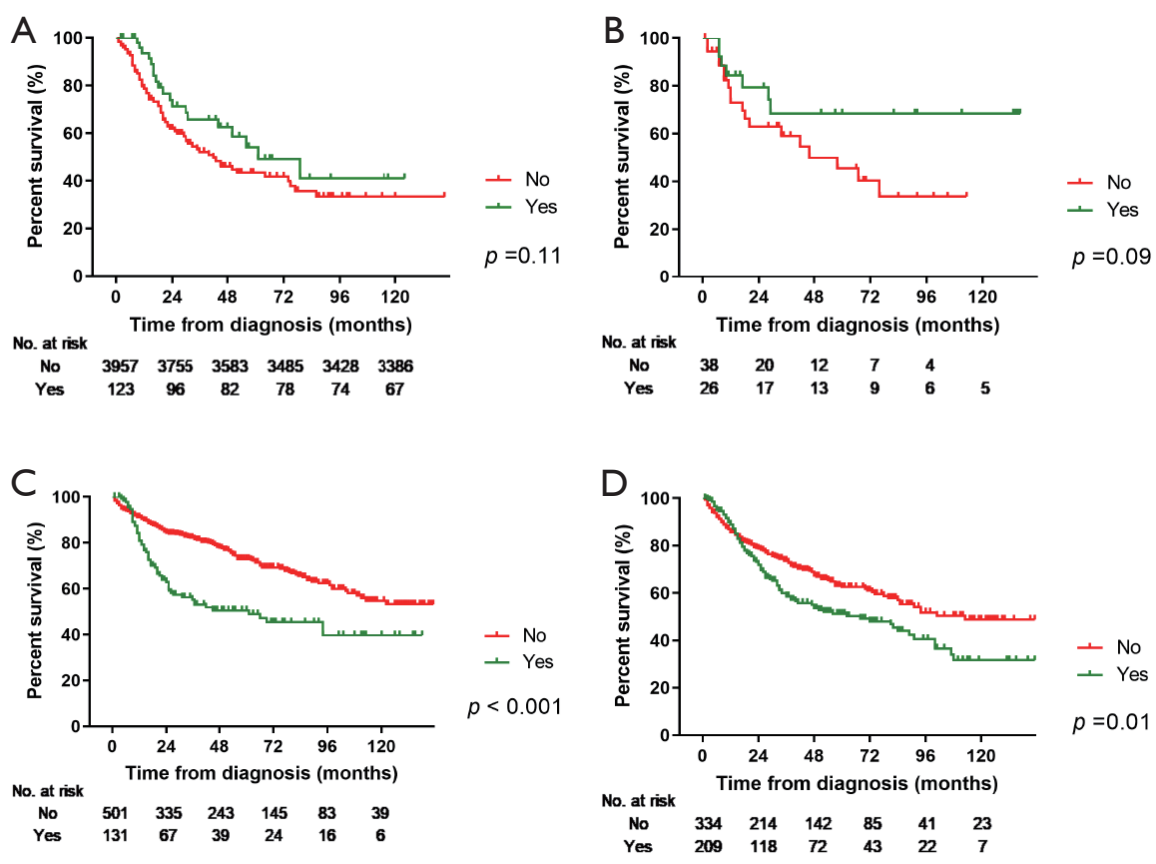

Figure S3 Overall survival by adjuvant chemotherapy according to the TNM staging system. (A) Stage IA, (B) stage IB, (C) stage II, and (D) stage III in the SEER cohort.
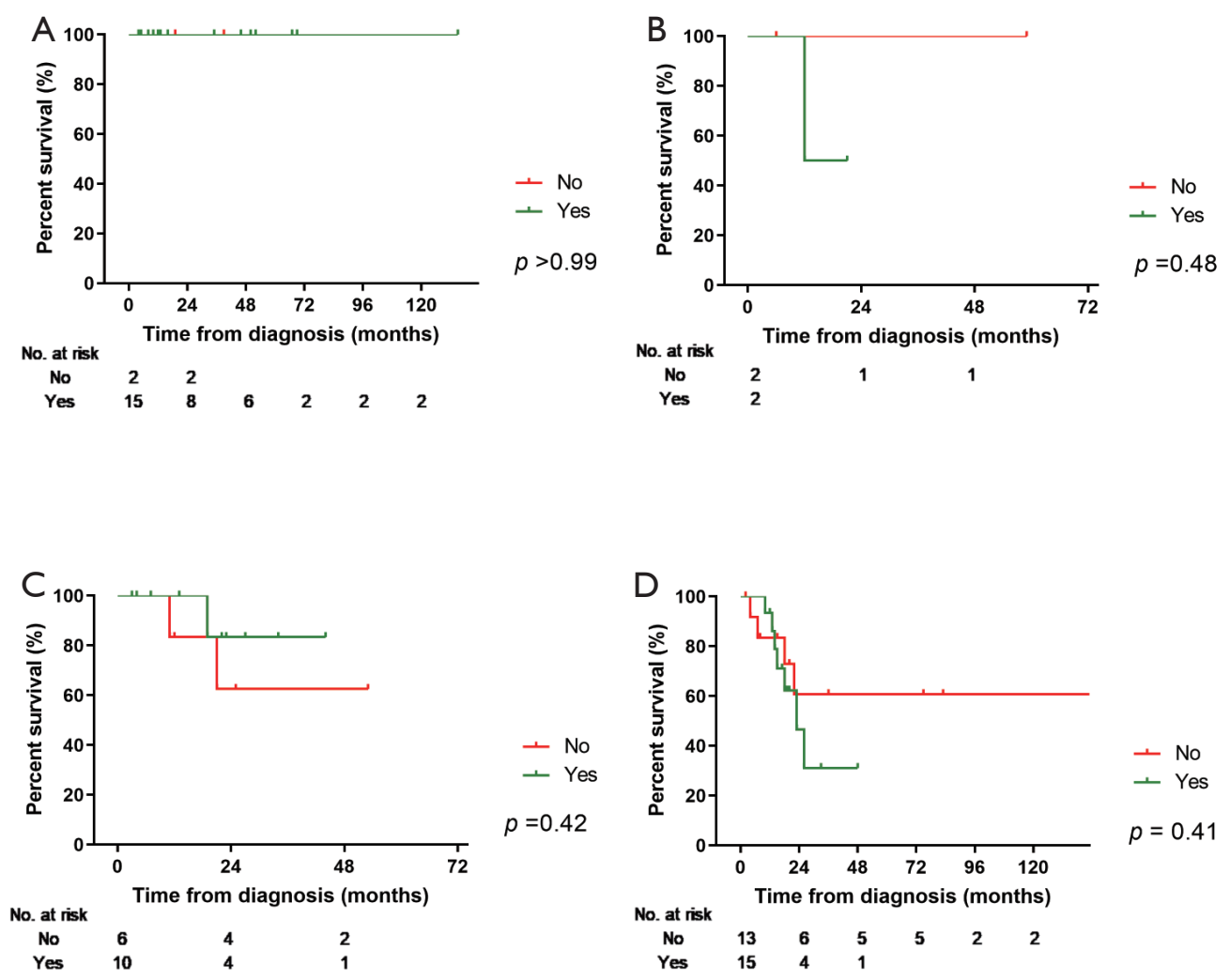

Figure S4 Overall survival by adjuvant chemotherapy according to the TNM staging system. (A) Stage IA, (B) stage IB, (C) stage II, and (D) stage III in the Shanghai cohort. 

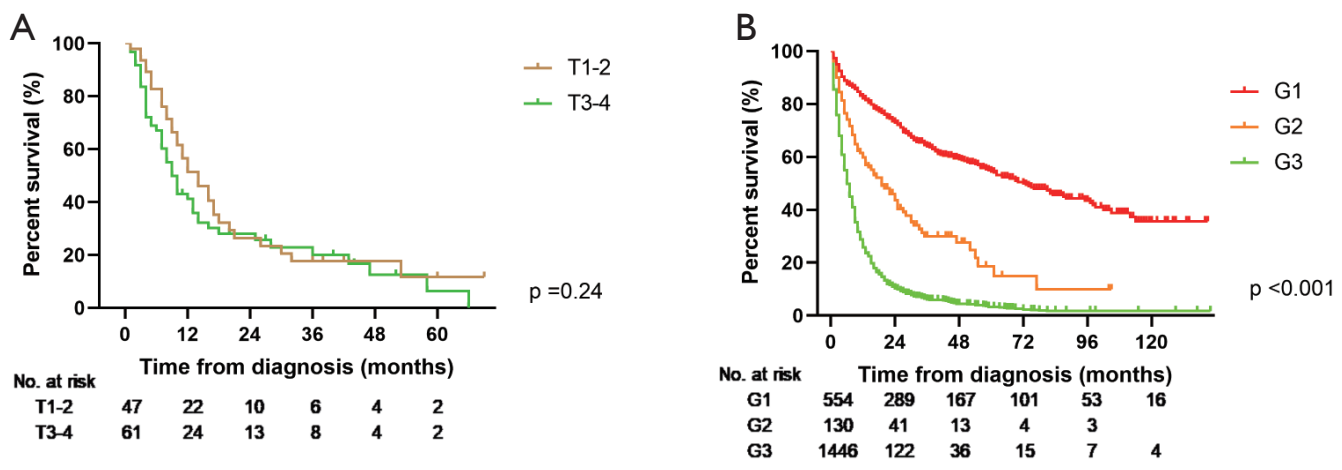

Figure S5 (A) Overall survival by histotype in patients with stage IIIC or IV tumors; (B) Overall survival by the T stage in patients with stage IIIC tumors. 